\title{
Ferroresonance simulations in radial systems using ATPDraw
}

\section{Simulaciones de ferroresonancias en sistemas radiales utilizando ATPDraw}

\author{
CETINA-ABREU, Rubén Joaquín†๋*, MADRIGAL-MARTÍNEZ, Manuel, TORRES-GARCÍA, Vicente \\ and CORONA-SÁNCHEZ, Manuel
}

Universidad Tecnológica de Campeche, México

Instituto Tecnológico de Morelia, México

Universidad Nacional Autónoma de México, México

Universidad Autónoma de la Ciudad de México, México

ID $1^{\text {st }}$ Author: Rubén Joaquín, Cetina-Abreu / ORC ID: 0000-0003-3941-8706, CVU CONACYT ID: 322913

ID $1^{\text {st }}$ Co-author: Manuel, Madrigal-Martínez / ORC ID: 0000-0003-1733-7673, CVU CONACYT ID: 25383

ID $2^{\text {nd }}$ Co-author: Vicente, Torres-García / ORC ID: 0000-0002-7540-5331, CVU CONACYT ID: 217253

ID $3^{\text {rd }}$ Co-author: Manuel A., Corona-Sánchez / ORC ID: 0000-0002-0530-6493, CVU CONACYT ID: 590550

DOI: $10.35429 /$ EJT.2021.10.5.1.10

Received July 20, 2021; Accepted December 30, 2021

\section{Abstract}

Fundamental parts of an electrical system are radial systems, which may be operating at different voltage levels, where an unwanted event such as ferroresonance is possible to occur. The conditions for the presence of a ferroresonance in an electrical system can present high overvoltages that can result in damage to critical equipment, high costs of corrective maintenance and plant shutdowns. These impacts mentioned justify the importance of analyzing, predicting and being able to establish strategies that avoid ferroresonance. In the present work simulations of radial feeders are shown where the ferroresonance event is presented as well as strategies to mitigate it by observing the behavior of voltage signals through simulations in the ATPDraw software.

Ferroresonances, Underground power cables, Transformers

\begin{abstract}
Resumen
Los sistemas radiales son considerados como una parte fundamental en los sistemas eléctricos, los cuales pueden operar en diferentes niveles de voltaje, donde eventos no deseados como la ferroresonancia es posible de ocurrir. Las condiciones para la presencia de la ferroresonancia en un sistema eléctrico pueden presentar altos niveles de voltaje que pueden resultar en daños a equipos críticos, altos costos de mantenimientos correctivos y paradas de plantas. Estos impactos mencionados justifican la importancia de analizar, predecir y ser capaz de establecer estrategias que eviten la ferroresonancia. En el presente trabajo simulaciones de alimentadores radiales son mostrados donde el evento de la ferroresonancia es presentado así como estrategias para mitigarla observando el comportamiento de las señales de voltaje mediante simulaciones en el software ATPDraw.
\end{abstract}

Ferroresonancia, Cables de potencia subterráneos, Transformadores

Citation: CETINA-ABREU, Rubén Joaquín, MADRIGAL-MARTÍNEZ, Manuel, TORRES-GARCÍA, Vicente and CORONA-SÁNCHEZ, Manuel. Ferroresonance simulations in radial systems using ATPDraw. ECORFAN Journal-Taiwan. 2021. 5-10: 1-10

$\dagger$ Researcher contributing as first author. 


\section{Introduction}

Different types of electrical systems operating at different voltage levels can present undesirable situations such as ferroresonance. Currently it is possible to observe the demand for reliable systems, avoid unforeseen stops that cause economic losses, be able to consider all possible failure events that may arise and develop strategies to avoid or mitigate them. In electrical signal studies, ferroresonance problems can be events that can cause damage to critical equipment, production stoppages, and high corrective maintenance costs. Therefore, ferroresonance is currently being analyzed in various contexts of electrical system operation [1].

Ferroresonance has the characteristic of presenting voltage distortions with high magnitudes, which can be above the nominal values [2]. On the other hand, the connection configurations of the transformers in the systems contribute to the presence of ferroresonance, mainly in the switching of three-phase disconnectors $[3,4]$.

Another situation that can be discussed is that radial feeder circuits are common to find through the use of power cables, presenting significant values of capacitances, which if they are connected to inductive equipment and there are certain closing and opening operations due to various situations, the system is susceptible to the presence of ferroresonance. In this article, ATPDraw simulations of a radial circuit are presented, showing the ferroresonance event and different strategies to avoid it.

\section{Fundamental concepts}

In 1920, Boucherot began with the analysis of ferroresonance, describing a complex resonant oscillation in an RLC circuit with a non-linear inductance [5]. The behavior of ferroresonance is through voltage signals in the form of aperiodic oscillations presenting transient overvoltages, mainly in transformers, and it can be of the series or parallel type. There are four modes: fundamental, sub harmonic, quasiperiodic and chaotic [6]. This phenomenon must be considered in the design of electrical systems since there are several prone configurations [7], as mentioned below:
Transformer accidentally fed in one or two phases, transformer energized through a capacitive gradient by opening one or two more switches, transformer connected to a series compensated transmission line, transformer connected to an isolated neutral (distribution) system, Coupling Capacitive Voltage Transformer, transformer connected to nonenergized lines in parallel with one or more lines energized, lightly loaded power transformer connected to an underground cable and transformer fed through a long transmission line or cable with small short-circuit power.

To have a better understanding of the phenomenon, a series electrical circuit is used, as shown in Fig. 1 which is made up of a series capacitor and a non-linear inductance.

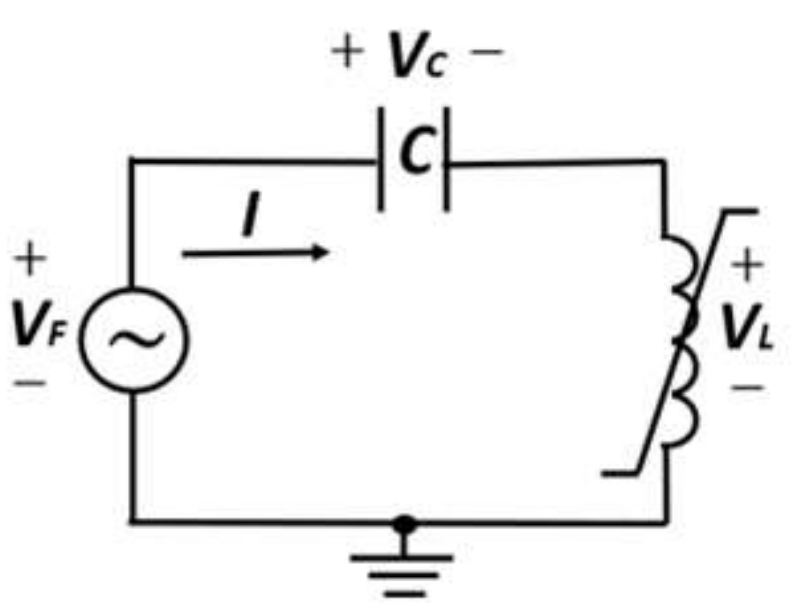

Figure 1 Electrical circuit prone to serie ferroresonance

From Fig. 1, and applying Kirchhoff's law for voltage in the analysis of a series-type ferroresonance, the following equation is obtained:

$V_{L}=V_{F}+j \frac{1}{\omega C} I$

Where $V_{F}$ is the source voltage, $\omega$ is the angular frequency and $C$ is the value of the capacitance. On the other hand, the voltage across the non-linear inductance is given by:

$V_{L}=j \omega L(I) I$

Where $L(I)$ is the non-linear characteristic of the inductor. To understand the complex behavior of ferroresonance, an analysis is first performed graphically. 
In Fig. 2, the point $\mathrm{P}$, which is the intersection of (1) and (2), is considered as an operating point, where the segment $\overrightarrow{P Q}$ corresponds to the voltage across the capacitor $V_{C}$ and the segment $\overrightarrow{P B}$ to the voltage across the inductor $V_{L}$. It is important to mention that if only the source voltage is applied to the capacitor, then there is a large $I_{C}$ current, and if only the source voltage is applied to the inductor, there will be a small current $I_{L}$.

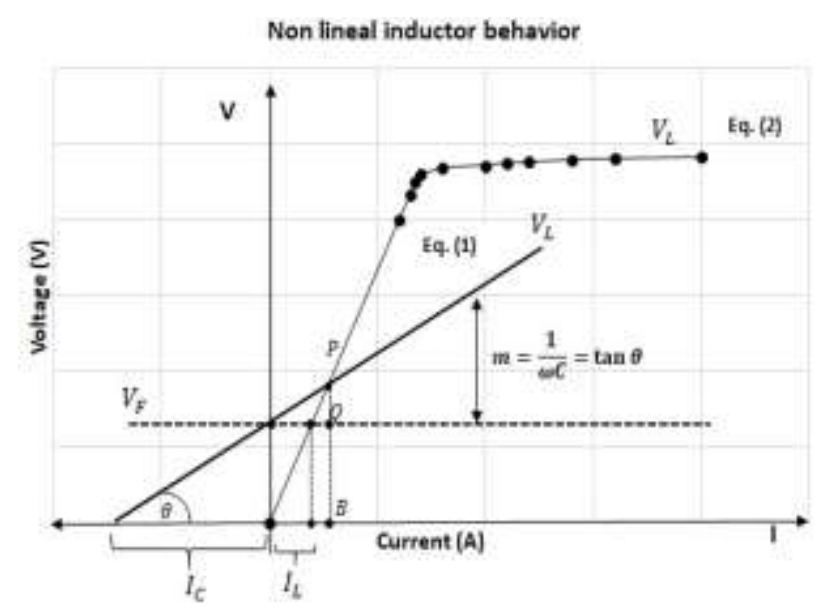

Figure 2 Graphs of voltage in the non-linear inductor.

If the parameters are considered to be fixed and only the value of the capacitance $\mathrm{C}$ or $\omega$ is varied, then it can be seen how the slope of the straight line intersects the curve, as shown in Fig. 3. The figure shows three points of intersection that can be interpreted as follows: two stable points 1 and 2 and one unstable 3 . Point 2 corresponds to normal operation in the linear region, with excitation current and flux within design limits.

Point 1 corresponds to the ferroresonant condition, characterized by a saturated flow and a large excitation current, and point 3 is considered an unstable point. If the capacitance is small, a $z$ point will appear, in this condition a sustained ferroresonance occurs, this is because the capacitance is very small.

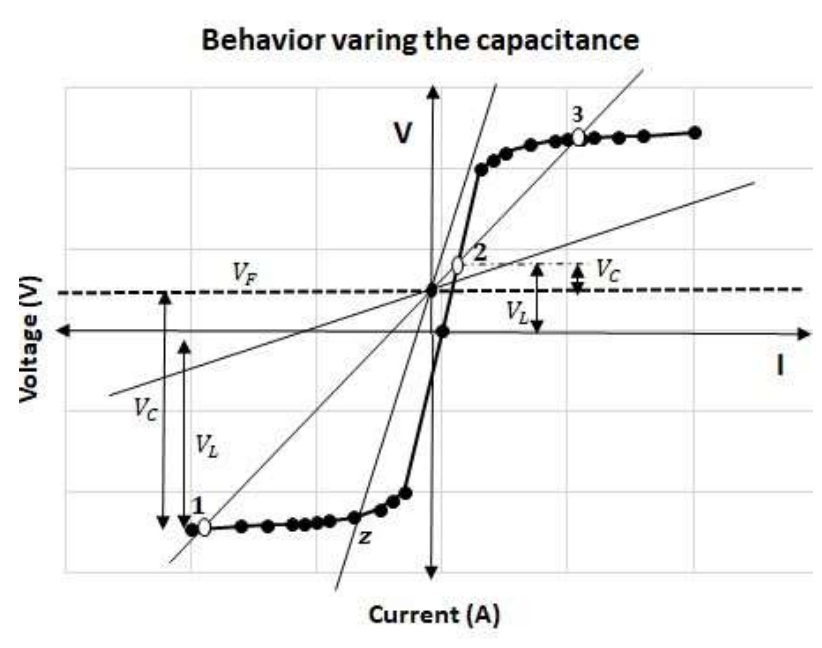

Figure 3 Presence of ferroresonance due to changes in capacitance

It can be seen that the main characteristic of a ferroresonant circuit is that it has at least two stable points, which produces a sudden increase in current or voltage from one stable operating point to another [8]. The end point of operation will depend on the initial conditions (residual flux, capacitance and value of the voltage source).

Another way that ferroresonance can occur is by varying the supply voltage levels of the source, this produces an upward movement in the linear equation (1) presenting current increases in points 1 and 2 . However, at point 3 there is a decrease, this is considered an unstable point, which is not physically possible $[9,10]$, as shown in Fig. 4.

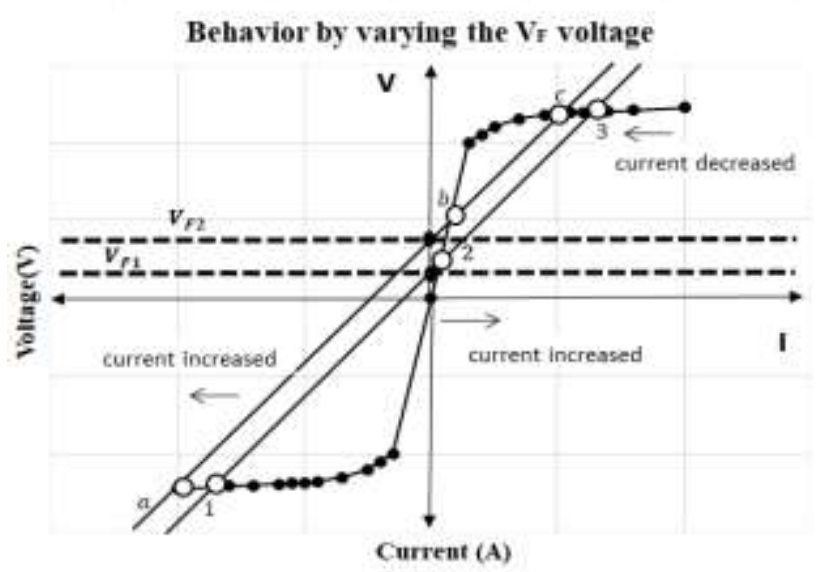

Figure 4 Presence of ferroresonance due to changes in capacitance 


\section{Ferroresonances conditions}

In different radial systems of different operating contexts, a large number of non-linear inductances can be found, such as the saturation characteristics of power transformers, inductive voltage transformers, as well as capacitive effects, such as power cables underground, wind turbine harmonic filters, capacitor voltage transformers, reactive power compensation capacitors and circuit breakers with capacitive gradients. Therefore, scenarios susceptible to the phenomenon of ferroresonance may occur and consequently, reduce the reliability of the system $[11,12]$.

Table 1 shows some ferroresonance phenomena that have occurred in a three-phase system.

\begin{tabular}{|c|c|c|}
\hline Phenomenon & $\begin{array}{c}\text { Cause of failure } \\
\text { event }\end{array}$ & $\begin{array}{l}\text { Effect of the } \\
\text { failure event }\end{array}$ \\
\hline \multirow[t]{3}{*}{$\begin{array}{l}\text { Ferroresonance in } \\
\text { power } \\
\text { transformers, feed } \\
\text { in one or two } \\
\text { phases }\end{array}$} & $\begin{array}{l}\text { Opening of one or } \\
\text { two phases, } \\
\text { configuration of the } \\
\text { system, transformer } \\
\text { connection delta- } \\
\text { wye, poles stuck in } \\
\text { the power circuit } \\
\text { breaker. }\end{array}$ & \multirow[t]{3}{*}{$\begin{array}{l}\text { Distorted } \\
\text { overvoltages, } \\
\text { heating in the } \\
\text { windings of the } \\
\text { transformer, } \\
\text { tripping } \\
\text { protections and } \\
\text { explosions } \\
\text { equipment }\end{array}$} \\
\hline & $\begin{array}{l}\text { Feeding the feeder } \\
\text { of the collecting } \\
\text { network in one or } \\
\text { two phases due to a } \\
\text { clogging in the } \\
\text { feeder } \\
\text { breaker. }\end{array}$ & \\
\hline & $\begin{array}{l}\text { A pole stuck in the } \\
\text { power circuit } \\
\text { breaker. }\end{array}$ & \\
\hline
\end{tabular}

Table 1 Evento de ferroresonancia en un transformador [11]

Table 2 shows some ferroresonance phenomena that have occurred due to a singlephase fault.

\begin{tabular}{|l|l|l|}
\hline \multicolumn{1}{|c|}{ Failure event } & \multicolumn{1}{|c|}{$\begin{array}{c}\text { Cause of } \\
\text { failure event }\end{array}$} & \multicolumn{1}{c|}{$\begin{array}{l}\text { Effect of the } \\
\text { failure event }\end{array}$} \\
\hline $\begin{array}{l}\text { Ferroresonance due } \\
\text { to a single-phase } \\
\text { fault on a } 33 \mathrm{kV} \text { bus }\end{array}$ & $\begin{array}{l}\text { Wiring } \\
\text { problem in } \\
\text { the union of } \\
\text { the electrical } \\
\text { system }\end{array}$ & $\begin{array}{l}\text { Voltage } \\
\text { distortions }\end{array}$ \\
\hline
\end{tabular}

Table 2 Ferroresonance due to single phase fault [12]
Conditions for the presence of ferroresonance [12]:

A. Presence of capacitive values with nonlinear inductances.

Underground cables and long overhead transmission lines are very common to find in a main substation of some system. Long overhead transmission lines and underground cables have significant capacitance to ground. Also, some equipment such as double-feed induction generators (DFIGs) and transformers have nonlinear inductances.

B. Lightly loaded system components (power transformers or measuring instruments)

During low wind speeds, wind farms have a small power generation and the collector transformer is slightly loaded, such a condition can present resonance and ferroresonance conditions. Fig. 5 shows a typical radial system in wind farms where the phenomenon of ferroresonance can occur.

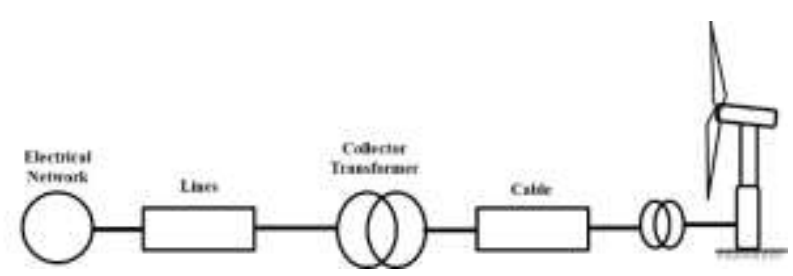

Figure 5 Radial electrical system prone to ferroresonance.

A radial electrical system can be represented as an LC series circuit, which is exposed to the phenomenon of ferroresonance. Some of these possible circuits are shown in Fig. 6 and Fig. $7[4,8,13]$.

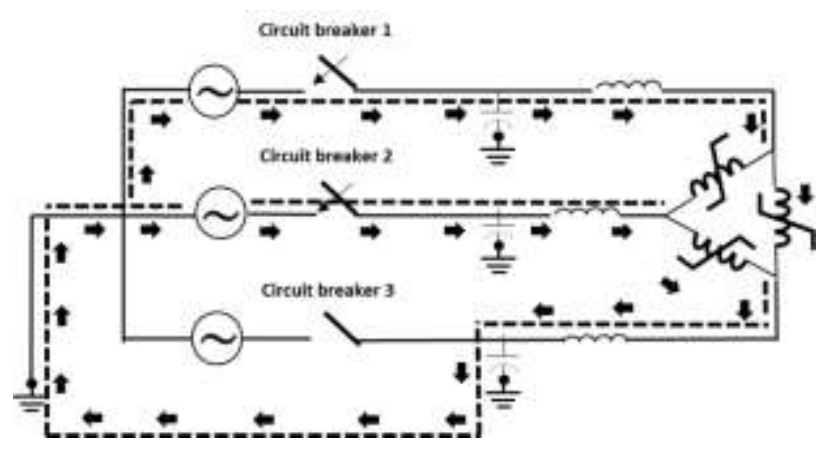

Figure 6 Presence of ferroresonance due to the opening of a phase 


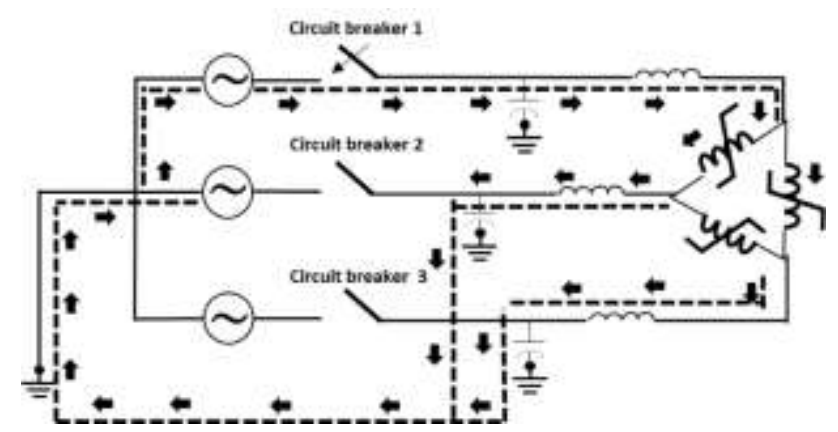

Figure 7 Presence of ferroresonance due to the opening of two phases

Analyzing the configurations of figures 6 and 7 , a type of ferroresonance can occur that causes a slow degradation of function $[14,15]$ or abrupt failures causing damage to critical equipment and components [16]. An event presented in a condition of degradation of the function of a critical equipment or component, such as premature aging and that is not considered, can result in unforeseen shutdowns of an electrical system.

\section{Parameterization of cables in ATPDraw}

To simulate the phenomenon of ferroresonance, a reliable cable parameterization is important, in this sense, in the ATPDraw program, the mode for cables is available for parameterization and can be composed of up to three concentric cylindrical layers of insulationconductor pair : main conductor and main insulation; metal screen and screen insulation; metallic armor and external insulation. This cable structure is shown in Fig. 8:

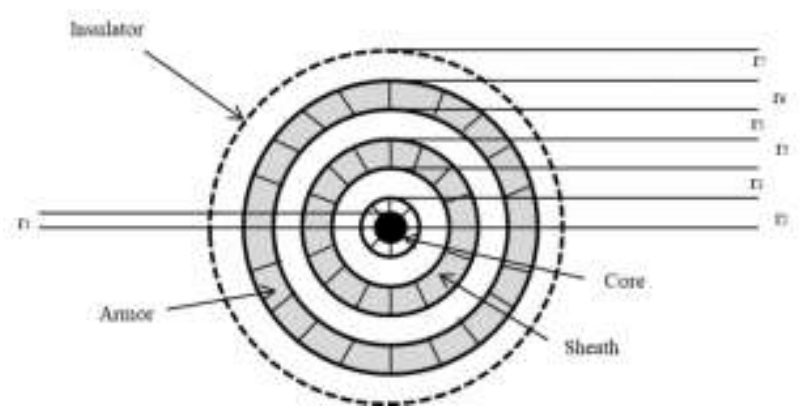

Figure 8 Parameters considered in cable simulation.

\section{Lightning arrester for transformer protection}

One of the important elements for the protection of transient surges is the arrester. This element is a non-linear resistor, which works as a function of voltage. For normal voltage values, this element has a very high resistance and therefore acts as an open circuit.
For high voltage values, the resistance decreases appreciably and therefore the element acts as ground leakage currents with a low voltage drop. The surge arrester model used in the present simulation is of the zinc oxide type. It is a non-linear resistor with a zinc oxide metal varistor (MOV). An important parameter that is considered in this item is the maximum continuous operating voltage (MCOV), which is the maximum voltage value that can be applied to the unit in continuous operation.

\section{Ferroresonance simulation in ATPDraw}

The transformers coupled to different systems can be connected in delta, such connection can present a ferroresonance, as shown in Figs. 6 and 7. For a better understanding of the phenomenon of ferroresonance, simulations are presented in ATPDraw, showing different behaviors in different cases. The electrical system analyzed is shown in Fig. 9. For the simulations carried out, a lightly loaded feeder is considered. For the simulation in ATPDraw, the sampling data are: $\Delta T=4 \times 10^{-5} \mathrm{~s}$ and $T_{\max }=1 \mathrm{~s}$.

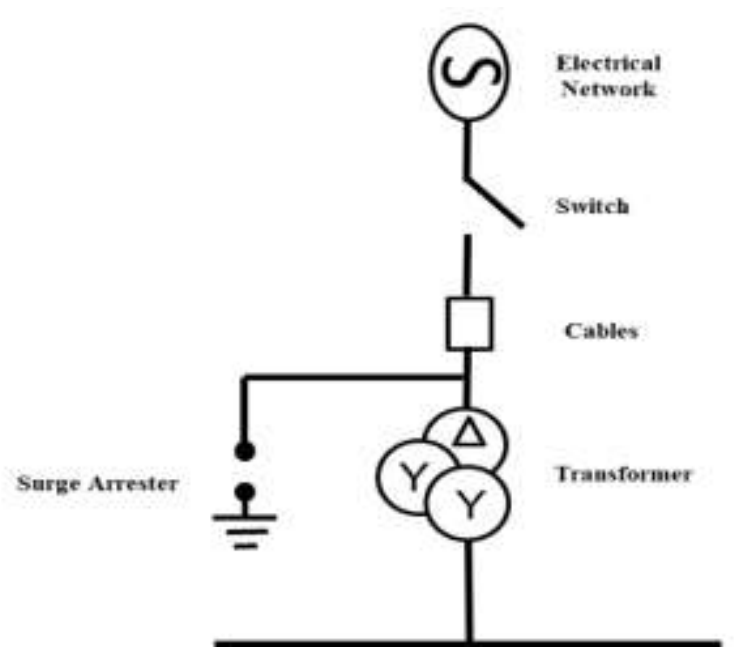

Figure 9 Electrical system analyzed

The power supply voltage is $23 \mathrm{kV}$ at a frequency of $60 \mathrm{~Hz}$, a phase angle of $0^{\circ}$ and a grounded system for underground cables. The zero and positive sequence Thevenin equivalent impedance is $Z_{0}=1.13129+j 3.37648 \Omega$ y $Z_{+}$ $=0.243+j 2.62445 \Omega$, respectively. The model used to carry out the simulations of the arresters is a non-linear resistance that has the characteristic saturation curve shown in Table 3.

CETINA-ABREU, Rubén Joaquín, MADRIGAL-MARTÍNEZ, Manuel, TORRES-GARCÍA, Vicente and CORONA-SÁNCHEZ, Manuel. Ferroresonance simulations in radial systems using ATPDraw. ECORFAN Journal-Taiwan. 2021 


\begin{tabular}{|r|r|}
\hline \multicolumn{1}{|c|}{ Voltage(V) } & Current (A) \\
\hline 26.8333333 & 0.001 \\
\cline { 2 - 2 } 38.3333333 & 0.01 \\
\cline { 2 - 2 } 39.8666667 & 0.1 \\
\cline { 2 - 2 } & 1 \\
\hline 41.4 & 10 \\
\hline 44.4666667 & 100 \\
\hline 46 & 1000 \\
\hline 50.5784375 & 10000 \\
\hline 59.8 &
\end{tabular}

Table 3 Characteristic of the $23 \mathrm{kV}$ arrester saturation curve

The underground cables in ATPDraw were modeled with a continuous neutral conductor grounded to earth, resistance to earth is also considered, Fig. 10 shows the cable model with 7 terminals and 4 cables. For the simulation of the passive branch of the circuit, the Pi model circuit is used.

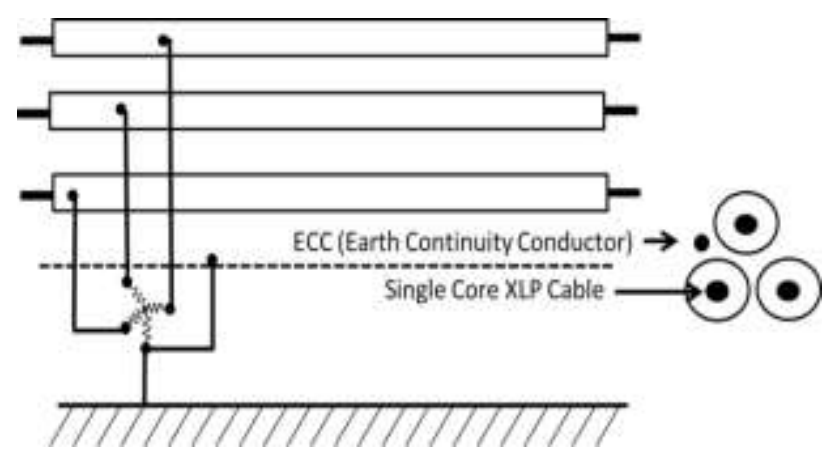

Figure 10 Cable configuration

The characteristics of the $23 \mathrm{kV}$ cables used in the simulation are shown in Table 4.

\begin{tabular}{|c|c|c|}
\hline Abbreviation & Core & Sheath \\
\hline $\operatorname{Rad}$ in $(\mathrm{m})$ & 0 & 0.02295 \\
\hline Rad out (m) & 0.01335 & 0.023593 \\
\hline$\rho\left(\Omega^{*} \mathrm{~m}\right)$ & $1.85 \mathrm{E}-08$ & $2.02 \mathrm{E}-07$ \\
\hline$\mu$ & 1 & 1 \\
\hline$\mu$ (ins) & 1 & 1 \\
\hline eps(ins) & 3.8436 & 5 \\
\hline
\end{tabular}

Table 4 Characteristic of $23 \mathrm{kV}$ cables

For the shielding and the continuous neutral conductor grounded to earth, a resistance of $1 \times 10^{-5} \Omega$ is considered. Its characteristics are shown in Table 5.

\begin{tabular}{|l|r|}
\hline Abbreviation & \multicolumn{2}{|c|}{ Core } \\
\hline $\operatorname{Rad}$ in $(\mathrm{m})$ & 0 \\
\hline $\operatorname{Rad}$ out $(\mathrm{m})$ & 0.00764 \\
\hline$\rho\left(\Omega^{*} \mathrm{~m}\right)$ & $2.55 \mathrm{E}-08$ \\
\hline$\mu$ & 1 \\
\hline$\mu($ ins $)$ & 1 \\
\hline$\varepsilon$ (ins) & 2.35 \\
\hline
\end{tabular}

Table 5 Characteristic of Earth Continuity Conductor
The geometric location used for the simulation is shown in Table 6.

\begin{tabular}{|l|r|r|}
\hline \multicolumn{1}{|c|}{ Cables } & \multicolumn{1}{c|}{$\mathbf{x}(\mathbf{m})$} & \multicolumn{1}{c|}{$\mathbf{y}(\mathbf{m})$} \\
\hline $\mathrm{a}$ & 0.028 & -1.5485 \\
\hline $\mathrm{b}$ & -0.028 & -1.5485 \\
\hline $\mathrm{c}$ & 0 & -1.5 \\
\hline $\mathrm{ECC}$ & 0.0389 & -1.5109 \\
\hline
\end{tabular}

Table 6 Geometry used for conductors

A resistance of $2 \mathrm{Ohms}$ is considered due to the resistivity of the soil. For the selection of the transformer, the SATTRAFO model in ATPDraw was chosen, with three windings, which considers the values of the saturation curve, the steady-state magnetic flux, the magnetizing resistance and a magnetizing current. The parameters used for the saturation curve are shown in Table 7.

\begin{tabular}{|r|r|}
\hline \multicolumn{1}{|c|}{ Current (A) } & Fluxlinked (Wb-T) \\
\hline 0.01689289 & 14.8532 \\
\hline 0.05067868 & 30.849 \\
\hline 0.1689289 & 49.5107 \\
\hline 0.5067868 & 59.8563 \\
\hline 1.689289 & 64.5792 \\
\hline 5.067868 & 66.0687 \\
\hline
\end{tabular}

Table 7 Saturation Curve

The transformer parameters are shown in Table 8 .

\begin{tabular}{|l|r|r|r|}
\hline Abbreviation & \multicolumn{1}{c}{ Prim. } & \multicolumn{1}{c|}{ Sec. } & \multicolumn{1}{c|}{ Tert. } \\
\hline Voltage $(\mathrm{V})$ & 23000 & 220 & 23000 \\
\hline $\mathrm{R}(\Omega)$ & 1.672 & 0.0001549 & 15.66 \\
\hline $\mathrm{XL}(\Omega)$ & 26.08 & 0.002415 & 58.28 \\
\hline Coupling & Delta & Wye & Wye \\
\hline Phase shift & 30 & & 30 \\
\hline I0 $(\mathrm{A})$ & & & 0.1332 \\
\hline Rm $(\Omega)$ & & 1306000 \\
\hline F0 $($ Wb-T $)$ & & 49.5107 \\
\hline
\end{tabular}

Table 8 Transformer characteristics

Delta connections are considered on the primary side and star on the secondary and tertiary side.

\section{A. Ferroresonance due to sequential closing of switches}

The system of Fig. 9 was used, the closing times for the switches are: $t=0 \mathrm{~s}, t=0.205 \mathrm{~s}$ y $t=$ $0.411 \mathrm{~s}$. The corresponding cable length is 1400 $\mathrm{m}$. 
Initially, only the closure of a single switch corresponding to phase A is considered, where the results with and without arresters are shown in Figs. 11 and 12.

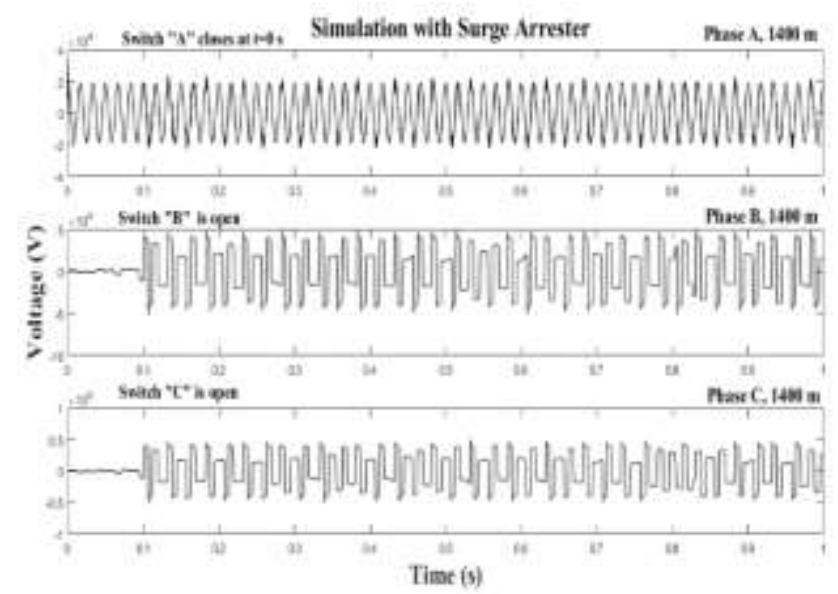

Figure 11 Presence of ferroresonance when only the switch A is closed with surge arrester

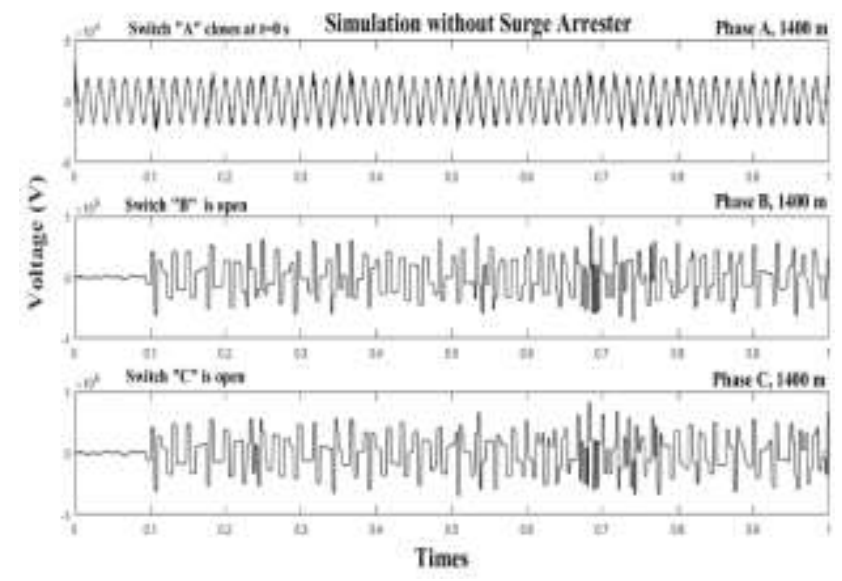

Figure 12 Presence of ferroresonance when only the switch A is closed, without surge arrester

In Figs. 11 and 12, it is possible to observe the ferroresonant voltage induced in phases B and C. In this condition, it is also shown that the system with arrester has smaller distorted voltage signal magnitudes.

For the following scenario analyzed, the disconnectors corresponding to phases $\mathrm{A}$ and $\mathrm{B}$ are closed, disconnector A closes at en $t=0 \mathrm{~s}$ and disconnector $\mathrm{B}$ at $t=0.205 \mathrm{~s}$, while the disconnector corresponding to phase $\mathrm{C}$ is open.

In this condition, the presence of inductive ferroresonance can be observed in phase $\mathrm{B}$ prior to the closing of the respective switch, as well as the sustained ferroresonance for phase C, as shown in Fig. 13 and 14.

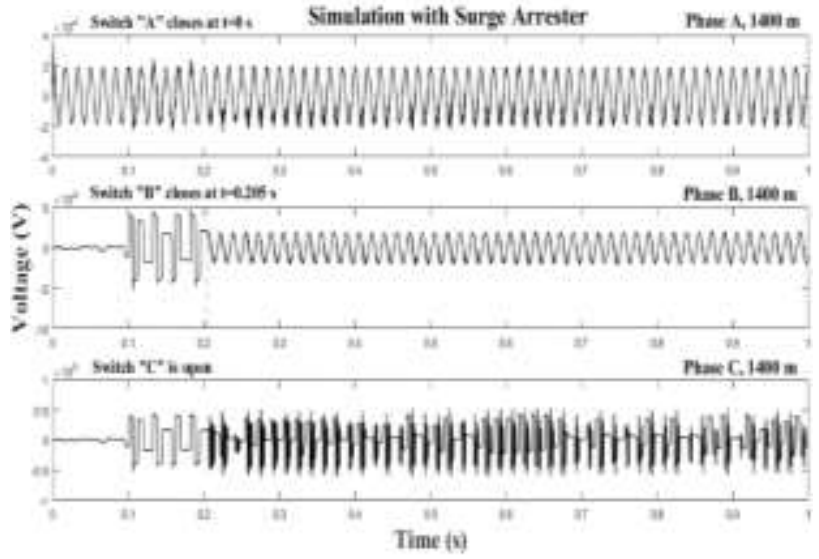

Figure 13 Presence of ferroresonance when switches A and $\mathrm{B}$ are closed, with surge arrester

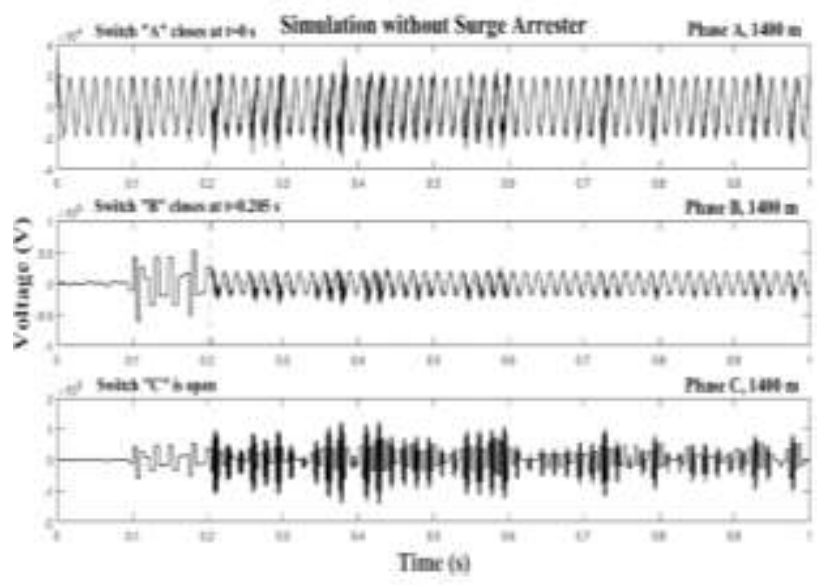

Figura 14 Presence of ferroresonance when switches A and $\mathrm{B}$ are closed, without surge arrester

For this other condition, the switches are closed consecutively. The switch corresponding to phase A closes at $t=0 \mathrm{~s}$, the switch corresponding to phase B closes at $t=0.205 \mathrm{~s}$ and the switch corresponding to phase $\mathrm{C}$ closes at $t=0.411 \mathrm{~s}$. In Fig. 15 and 16, it can be seen that there is only induced ferroresonance in phases $\mathrm{B}$ and $\mathrm{C}$ before closing their respective switches.

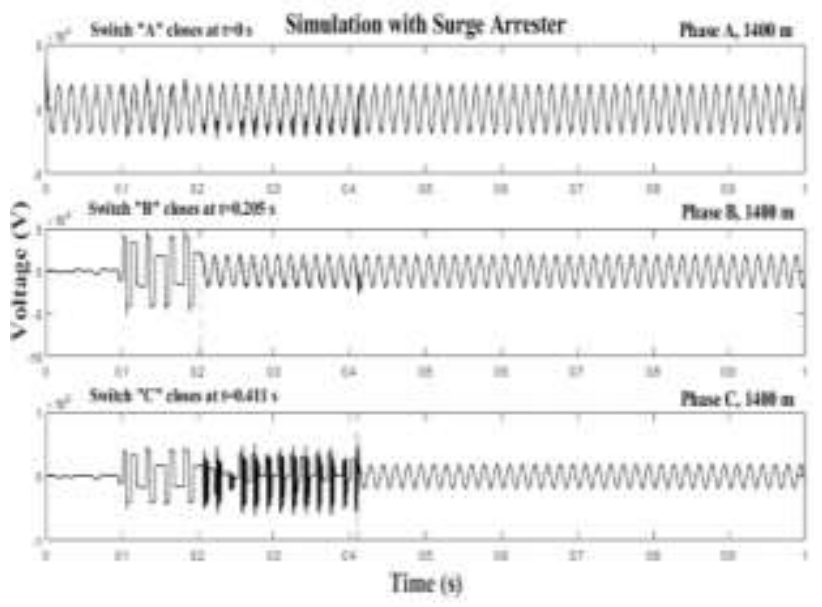

Figure 15 Presence of ferroresonance when switches A, B and $\mathrm{C}$ are closed, with surge

CETINA-ABREU, Rubén Joaquín, MADRIGAL-MARTÍNEZ, Manuel, TORRES-GARCÍA, Vicente and CORONA-SÁNCHEZ, Manuel. Ferroresonance simulations in radial systems using ATPDraw. ECORFAN Journal-Taiwan. 2021 


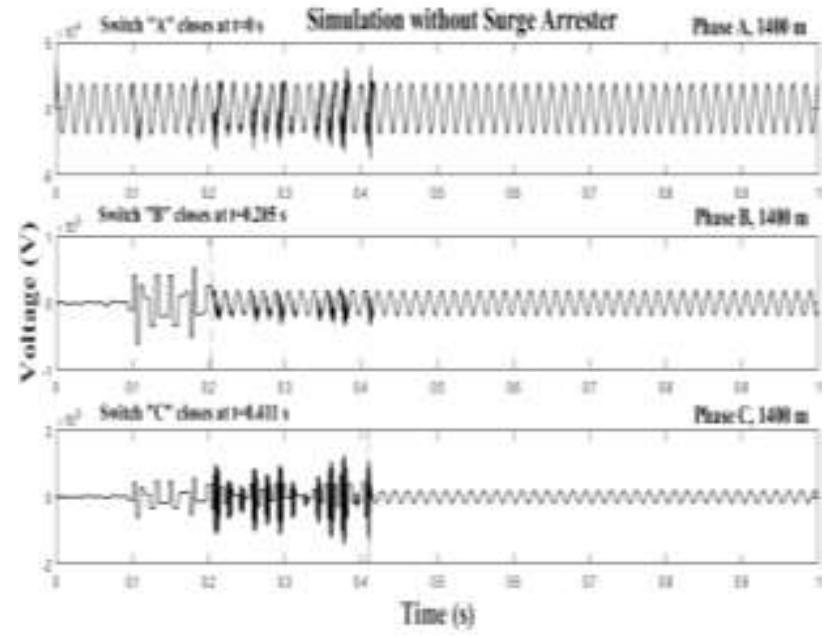

Figure 16 Presence of ferroresonance when switches A, B and $\mathrm{C}$ are closed, without surge arrester

\section{B. Switch relocation to mitigate ferroresonance}

If the switches are now relocated closer to the transformer, as shown in Fig. 17, then it can be seen that the ferroresonance is mitigated, this is because the capacitive effect of the cables is eliminated. It is mentioned that for a better appreciation of this condition in the simulation, the insertion of the arresters was not considered.

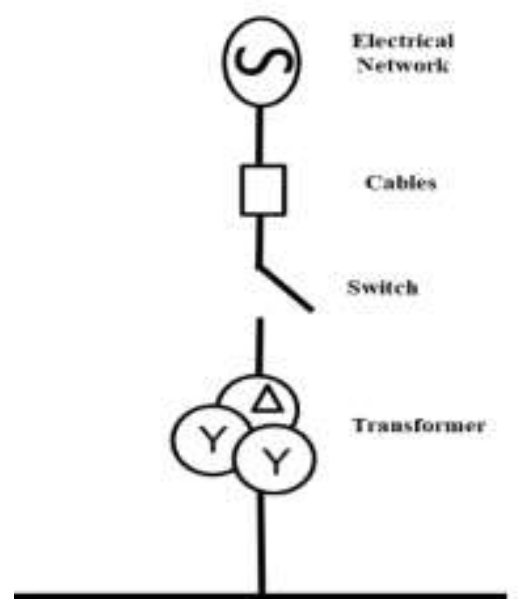

Figure 17 Electrical system with switches near to transformer

The closing times for the switches in this condition are: for the switch corresponding to phase A closes at $t=0 \mathrm{~s}$, the switch corresponding to phase $\mathrm{B}$ closes at $t=0.205 \mathrm{~s}$ and the switch corresponding to phase $\mathrm{C}$ closes at $t=0.411 \mathrm{~s}$. The behavior in the voltage signals is shown in Fig. 18 observing that the distortions of the voltage signals have been mitigated.

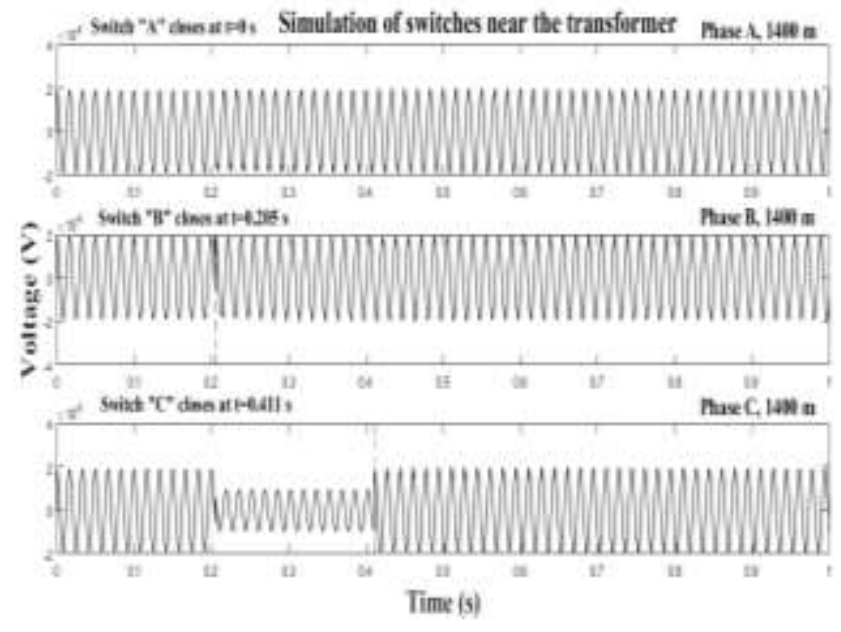

Figure 18 Ferroresonance mitigated due to change of switch location.

\section{Change delta to star connection on transformer}

Another way to mitigate ferroresonance for this electrical system is to change the transformer connection, that is, from delta connection to star connection, thus eliminating the LC path. The simulations are shown in Fig. 19. The closing times for the switches are the same as in the previous cases.

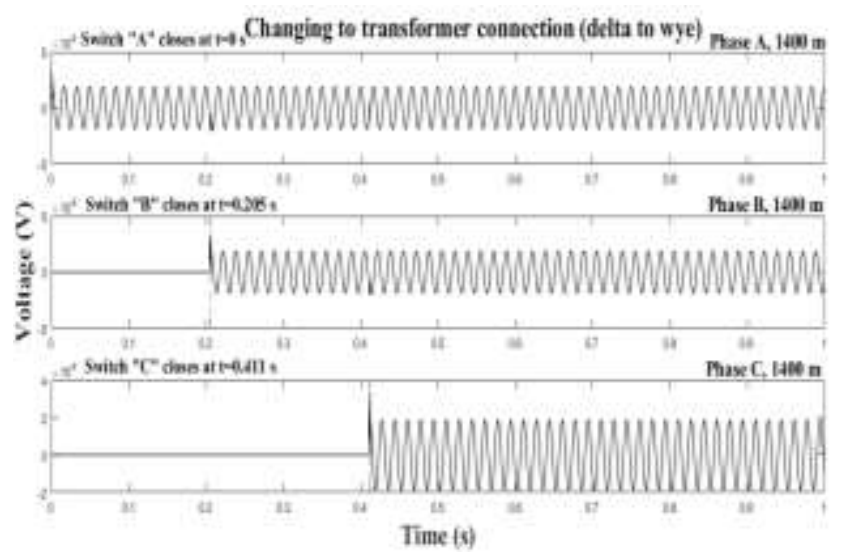

Figure 19 Behavior of voltage signals with star connection in the transformer

\section{Mitigation of ferroresonance due to switch closure}

Close all three switches at the same time. In this situation, induced ferroresonance is not allowed, as shown in Fig. 20. 


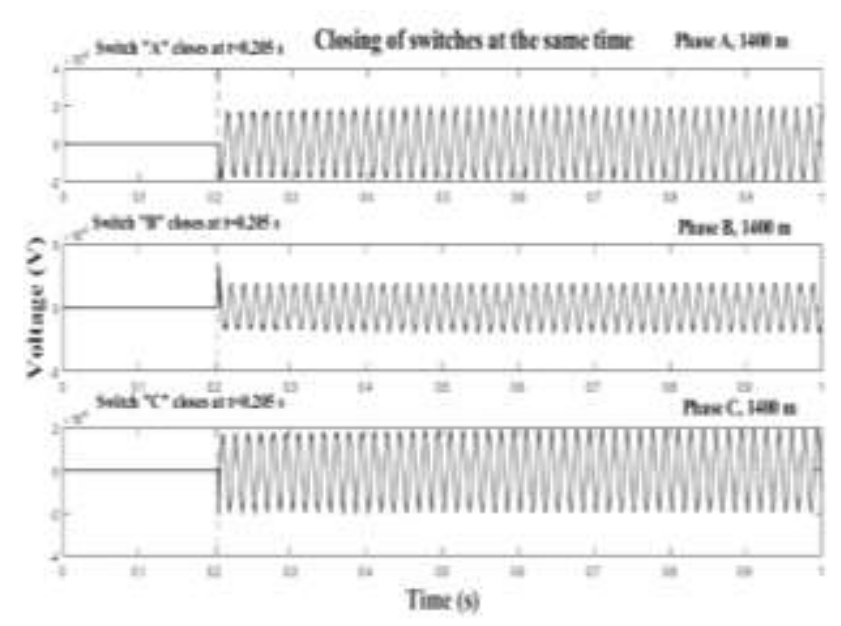

Figure 20 Behavior when closing the A, B and C switches closed at the same time.

\section{Conclusions}

The presence of ferroresonance in wind farms in a non-significant way, causes premature aging, reducing the life cycle of critical equipment such as the transformer, and can cause deficient maintenance programs and high costs for plant shutdowns. Simulations of the phenomenon of ferroresonance in underground cables corresponding to a wind farm show that the lightning rod in the electrical system reduces the impact on the magnitude of ferroresonances. The simulations carried out to mitigate the ferroresonance event show that there is a variety of possible solutions in the analyzed radial configuration, showing the importance of being considered in the designs of the electrical installations of wind farms. An area of opportunity is the economic evaluation of electrical designs in wind farms considering the reliability impacts due to the presence of ferroresonance, considering the calculation of the failure rate due to this phenomenon in critical equipment.

\section{Acknowledgment}

The authors thank the Universidad Tecnológica de Campeche specifically, the CIACIP, the Universidad Nacional Autónoma de México, the Instituto Tecnológico de Morelia and the Universidad Autónoma de Ciudad de México for having allowed the development of this publication together.

\section{References}

[1] E. A. Badran, M. E., M. Rizk, M.H, "Investigation of Ferroresonance in Offshore Wind Farms", Journal of American Science, 2011.

[2] F. Bem Amar, R. Dhifaoui, "Study of the periodic ferroresonance in the electrical power networks by bifurcation diagrams", Electrical Power and Energy Systems Research, Volume 33 Issue 1, Pages 61-85, January 2011.

[3] V. Preciado, M. Madrigal, E. Muljadi, V. Gevorgian, "Harmonics in Wind Power Plants", IEEE Power and Energy Society General Meeting, Denver, Colorado, 2015.

[4] R. Cetina, M. Madrigal, V. Torres, "Simulation of Ferroresonances in Transformers using ATP (Alternative Transient Program)," IEEE International Autumn Meeting on Power, Electronics and Computing (ROPEC). Ixtapa, México, 2018.

[5] P. Boucherot, "Existence de Deux Regimes en ferroresonance," R.G.E., pp. 827-828, Dec. 1920 (in French).

[6] P. Ferraci, Ferroresonance, Cahier Technique no 190, Groupe Schneider, 1998.

[7] Jacobson DAN, "Examples of Ferroresonance in high voltage power system." IEEE working group under T\&D general systems subcommittee, Prof. Bruce Mork, Chairman, Practical aspects of ferroresonance, 2003.

[8] R. Pérez, R. Rodríguez, A. Aguila, "Analysis and Simulation of Ferroresonance in Power Transformer using Simulink", IEEE Latin America Transactions, Vol. 16, No. 2, Feb. 2018, Pag. 460-466.

[9] Greenwood, Electrical Transients in Power System, 2nd ed. J Wiley \& Sons, Inc. 1991, pp 116-122.

[10] J. R. Martí, A. C. Soudack, "Ferroresonance in power system: Fundamental solution", IEE Proceedings C - Generation, Transmission and Distribution (Volume: 138, Issue: 4, July 1991. 
[11]U. Karaagac, J. Mahseredjian, L. Cai, "Ferroresonance conditions in wind parks", Journal Electric Power Systems Research, vol. 138, Pages 41-49, April 2016

[12]M. K. Siahpoosh1, D. Dorrell, L. Li1, Ferroresonance Assessment in a Case Study Wind Farm with 8 Units of 2 MVA DFIG Wind Turbines, 2017 20th International Conference on Electrical Machines and Systems (ICEMS).

[13] Mozina, C. J., "Impact of smart grids and green power generation on distribution systems," IEEE Trans. Ind. Appl., Vol. 49, No. 3, pp. 1079-1090, May-June 2013.

[14] S. Mišák, J. Fulneček, The influence of ferroresonance on a temperatura of voltage transformers in undeground mines, 2017 18th International Scientific Conference on Electric Power Engineering (EPE).

[15] M. Osborne, P. Jarman, "The impact of ferroresonance and low frequency phenomena on power transformers and transmission system", Journal of Energy, Vol. 59, 2010. Special Issue, p. 90-96.

[16] R. Martínez, M. Manana, J. I. Rodríguez, M. Alvarez, R. Minguez, A. Arroyo, E. Bayona, F. Azcondo, A. Pigazo, F. Cuartas, "Ferroresonance phenomena in medium voltage isolated neutral grids: a case study, IET Renew. Power Gener., 2019, Vol. 13 Iss. 1, pp. 209-214.

[17] Acha E., Madrigal M. Power System Harmonics, Computer Modelling and Analysis, Edit. John Wiley \& Sons, UK. 2001, Pag. 89-94.

[18]R. Walling, K. Barker, T. Compton, L. Zimmerman, "Ferroresonant overvoltages in grounded wye-wye padmount transformer with low loss silicon steels core", IEEE Transaction Power Delivery, Vol.8, No.3, pp. 1647-1660, July 1993.

[19]E. C. Lister, "Ferroresonance on rural distribution system", IEEE Transactions on industry applications, Vol. I-A9, No. 1, February 1973.
[20]L. B. Viena, F. A. Moreira, N. R. Ferreira, A. C. de Castro and N. C. de Jesus, Analysis and Application of Transformer Models in the ATP Program for the study of Ferroresonance, IEEE/PES Transmission and Distribution Conference and Exposition Latin America, 2010.

[21]E. A. Araujo, A. C. Soudack, and J. R. Marti, "Ferroresonance in power systems: chaotic behaviour," Proc. Inst. Elect. Eng. C, vol. 140, no. 3, pp. 237-240, May 1993. 